\title{
Formulation and Evaluation of Gastroretentive Drug Delivery System of Propranolol Hydrochloride
}

\author{
Swati C. Jagdale, ${ }^{1,5}$ Amit J. Agavekar, ${ }^{2}$ Sudhir V. Pandya, ${ }^{3}$ \\ Bhanudas S. Kuchekar, ${ }^{2}$ and Aniruddha R. Chabukswar ${ }^{4}$
}

Received 8 October 2008; accepted 27 July 2009; published online 12 August 2009

\begin{abstract}
The objective of present study was to develop a gastroretentive drug delivery system of propranolol hydrochloride. The biggest problem in oral drug delivery is low and erratic drug bioavailability. The ability of various polymers to retain the drug when used in different concentrations was investigated. Hydroxypropyl methylcellulose (HPMC) K4 M, HPMC E 15 LV, hydroxypropyl cellulose (HPC; Klucel HF), xanthan gum, and sodium alginate (Keltose) were evaluated for their gelforming abilities. One of the disadvantages in using propranolol is extensive first pass metabolism of drug and only $25 \%$ reaches systemic circulation. The bioavailability of propranolol increases in presence of food. Also, the absorption of various drugs such as propranolol through P-glycoprotein (P-gp) efflux transporter is low and erratic. The density of P-gp increases toward the distal part of the gastrointestinal tract (GIT). Therefore, it was decided to formulate floating tablet of propranolol so that it remains in the upper part of GIT for longer time. They were evaluated for physical properties, in vitro release as well as in vivo behavior. In preliminary trials, tablets formulated with HPC, sodium alginate, and HPMC E 15 LV failed to produce matrix of required strength, whereas formulation containing xanthan gum showed good drug retaining abilities but floating abilities were found to be poor. Finally, floating tablets were formulated with HPMC K4 M and HPC.
\end{abstract}

KEY WORDS: floating delivery; gastroretentive; hydroxypropyl methylcellulose; propranolol hydrochloride.

\section{INTRODUCTION}

Oral drug delivery has been known for decades as the most widely used route of administration among all the routes that have been explored for the systemic delivery. Oral route is the most convenient and extensively used route of drug administration. All controlled release systems have limited applications if the systems cannot remain in the vicinity of the absorption site. The controlled release drug delivery system possessing the ability of being retained in the stomach is called gastroretentive drug delivery system. They can help in optimizing the oral controlled delivery of drugs having "absorption window" continually releasing the drug prior to absorption window for prolonged period of time, thus ensuring optimal bioavailability (1). Gastric emptying occurs during fasting as well as fed states. The pattern of motility is, however, distinct in the two states.

\footnotetext{
${ }^{1}$ Department of Pharmaceutics, MAEER's Maharashtra Institute of Pharmacy, Pune, 411038 Maharashtra, India.

${ }^{2}$ MAEER's Maharashtra Institute of Pharmacy, Pune, 411038 Maharashtra, India.

${ }^{3}$ Quality Assurance, Nulife Pharmaceuticals, Pimpri, 411 018, Pune, Maharashtra, India.

${ }^{4}$ Department of Pharmaceutical Chemistry, MAEER's Maharashtra Institute of Pharmacy, Pune, 411038 Maharashtra, India.

${ }^{5}$ To whom correspondence should be addressed. (e-mail: jagdaleswati @rediffmail.com)
}

Gastric emptying studies revealed that orally administered controlled release dosage forms are subjected to basically two complications: that of short gastric residence time and unpredictable gastric emptying rate (2).

Propranolol is a nonselective beta-adrenergic receptor blocking agent possessing no other autonomic nervous system activity. It specifically competes with beta-adrenergic receptor agonist agents for available receptor sites. It is used as antihypertensive, antianginal, antiarrhythmic, and in treatment of migraine (3). Propranolol is reported to be of value in more than 20 noncardiovascular disorders, many of which are associated with central nervous system (4).

Propranolol is highly lipophilic and almost completely absorbed after oral administration. However, it undergoes high first-pass metabolism by the liver, and on average, only about $25 \%$ of propranolol reaches the systemic circulation. Approximately $90 \%$ of circulating propranolol is bound to plasma proteins. Propranolol is extensively metabolized with most metabolites appearing in the urine.

Peak plasma concentrations occur about 1 to $4 \mathrm{~h}$ after an oral dose. $t_{1 / 2}$ of propranolol is $3-4 \mathrm{~h} \mathrm{(5).}$

Thus, propranolol has relatively short half-life. Consecutively, for an optimum effect, the administration of propranolol hydrochloride as conventional tablets (with rapid disintegration and dissolution) must be carried out several times a day. Therapy with immediate release propranolol hydrochloride tablets typically requires $40-160 \mathrm{mg}$ as daily 
dose given in three to four divided doses (6). Presence of food increases the bioavailability. The secretory transporter P-glycoprotein (P-gp) located on the epithelium cells is responsible for low and variable bioavailability of various compounds such as propranolol (7).

Although P-gp appears to be distributed throughout the gastrointestinal tract (GIT), its levels are higher in more distal regions (stomach $<$ jejunum $<$ colon). Absorption through P-glycoprotein prolongs the drug exposure to CYP3A4.

The colocalization of P-gp and CYP3A4 in the mature enterocytes and their overlapping substrate specificity reasonably suggests that the function of these two proteins may be synergistic and appear to be coordinately regulated. Consequently, a greater proportion of drug will be metabolized since the repetitive two-way kinetics (drug exsorption from the enterocytes into the lumen via P-gp and reabsorption back into enterocyte) will simply prolong the drug exposure to CYP3A4. This mechanism not only limits the absorption of a wide variety of drugs, including peptides, but also poses a threat for potential drug interactions $(7,8)$.

Based on previously published literature, applications of gastroretentive drug delivery system (GRDDS) may be summarized for several categories of drugs (8) as drugs for local action in stomach, e.g., 5-flurouracil, antacids; drugs unstable in lower part of GIT, e.g., captopril; drugs insoluble in intestinal fluids (acid soluble basic drugs), e.g., propranolol, metoprolol, diazepam; drugs with variable bioavailability, e.g., sotalol hydrochloride, levo DOPA; and drugs with sitespecific absorption in stomach or upper parts of small intestine, e.g., atenolol, levo DOPA, salbutamol, sotalol.

As discussed earlier, propranolol has short half-life, high first-pass metabolism, presence of food increases the bioavailability, P-gp plays important role in the absorption, and the drug is acid-soluble basic drug which make it suitable for GRDDS. Till today, no floating drug delivery system has yet developed for propranolol. So, it was decided to formulate propranolol floating tablets.

Khattar et al. (9) formulated hydrodynamically balanced capsules as sustained release dosage forms for propranolol hydrochloride. Floating behavior of the hydrodynamically balanced system capsule was also seen in vivo with the help of endoscopy.

Bodea and Leucuta (10) optimized propranolol hydrochloride sustained release pellets using a conventional pan method. Eudragit RS was used as rate-controlling agent. The independent variable was plasticizer concentration in the coating and concentration of coating dispersion applied to the pellets in the coating pan.

Narendra et al. (11) formulated and optimized bilayered floating tablet containing metoprolol tartarate as a model drug for gastric retention. Different viscosity grades of hydroxypropyl methylcellulose (HPMC) were selected as independent variables. With different grades of HPMC (K4M and K10M), there was no significant change on gastric retention.

Ali et al. (12) formulated hydrodynamically balanced system for metformin as single unit capsule. Capsules prepared with HPMC K4M and ethyl cellulose gave the best in vitro percentage release. The formulation remained buoyant during $5 \mathrm{~h}$ of study in rabbits.

Basak et al. (13) formulated floating drug delivery of ciprofloxacin, a drug which is better absorbed from stomach and upper small intestine. HPMC K100 M was used as rate controlling polymer. In vitro drug release study of these tablets indicated controlled sustained release for ciprofloxacin and 80$89 \%$ release at the end of $8 \mathrm{~h}$. The objective of the present work was to develop matrix floating tablets and to study the effect of various polymers as HPMC K4 M, HPMC E $15 \mathrm{LV}$, hydroxypropyl cellulose (HPC), carbopol, and xanthan gum on the release of propranolol hydrochloride from the tablet, also to compare the formulated preparation for its release profile with marketed formulation, to calculate similarity factor, and to perform in vivo evaluation of optimized formulation.

\section{MATERIALS AND METHODS}

\section{Materials}

Propranolol hydrochloride was obtained as gift sample from Concept Pharmaceuticals, Aurangabad. HPMC (Methocel K4 M and E 15 LV, Colorcon Asia Ltd., Goa, India), HPC (Klucel HF, Aqualon, Signet Chemical Corporation), xanthan gum, and sodium alginate were obtained from Nulife Pharmaceuticals, Pimpri, Pune, India. All other chemicals used were of reagent grade.

\section{Methods}

Formulation of Propranolol Hydrochloride Floating Tablets (Preliminary Trials)

In preliminary studies, effect of various polymers on the release of drug was studied by formulating tablets with polymers in concentrations of $30 \%, 40 \%$, and $50 \%$. Total weight of tablet was $200 \mathrm{mg}$ (Table I). The tablets were directly compressed in 16 station rotary tablet press with oval flat-faced die punches of $8.5 \mathrm{~mm}$ diameter.

All the formulations contained $40 \mathrm{mg}$ of propranolol hydrochloride. Ten percent sodium bicarbonate as gas generating agent, mannitol as diluent, and magnesium stearate was $(1 \%)$ added as lubricant.

\section{Evaluation of Floating Tablets}

\section{Evaluation of powder blend}

The powder blend was evaluated for flow properties. Different tests that were carried out are angle of repose, loose bulk density, tapped bulk density, and compressibility index, and Hausner ratio was calculated.

\section{Evaluation of matrix tablets}

Tablets were subjected to various tests like hardness, friability, uniformity of drug content, and uniformity of mass of single dose preparation as per US Pharmacopeia (USP).

(a) In vitro buoyancy studies

In vitro buoyancy was determined by buoyancy lag time, floating duration, matrix integrity.

- Buoyancy lag time/lag time for floating of tablets

Buoyancy lag time test was performed to check the floating behavior. The tablets were dropped in the dissolution 
Table I. Tablet Formulations for Preliminary Trials

\begin{tabular}{|c|c|c|c|c|c|c|c|c|c|}
\hline Formulation & Drug & HPMC K4 M & HPMC E 15 LV & HPC & Xanthan gum & Sodium alginate & $\mathrm{NaHCO}_{3}$ & Mannitol & Magnesium stearate \\
\hline I & 40 & 60 & - & - & - & - & 20 & 78 & 2 \\
\hline II & 40 & 80 & - & - & - & - & 20 & 58 & 2 \\
\hline III & 40 & 100 & - & - & - & - & 20 & 38 & 2 \\
\hline IV & 40 & - & 60 & - & - & - & 20 & 78 & 2 \\
\hline V & 40 & - & 80 & - & - & - & 20 & 58 & 2 \\
\hline VI & 40 & - & 100 & - & - & - & 20 & 38 & 2 \\
\hline VII & 40 & - & - & 60 & - & - & 20 & 78 & 2 \\
\hline VIII & 40 & - & - & 80 & - & - & 20 & 58 & 2 \\
\hline IX & 40 & - & - & 100 & - & - & 20 & 38 & 2 \\
\hline $\mathrm{X}$ & 40 & - & - & - & 60 & - & 20 & 78 & 2 \\
\hline XI & 40 & - & - & - & 80 & - & 20 & 58 & 2 \\
\hline XII & 40 & - & - & - & 100 & - & 20 & 38 & 2 \\
\hline XIII & 40 & - & - & - & - & 60 & 20 & 78 & 2 \\
\hline XIV & 40 & - & - & - & - & 80 & 20 & 58 & 2 \\
\hline$X V$ & 40 & - & - & - & - & 100 & 20 & 38 & 2 \\
\hline
\end{tabular}

Total weight of tablet $200 \mathrm{mg}$. All weights in milligrams

HPMC hydroxypropyl methyl cellulose, HPC hydroxypropyl cellulose

medium, i.e., $0.1 \mathrm{~N} \mathrm{HCl}$ and the time taken by them to come to the surface of the dissolution medium, i.e., time taken for floating on surface was reported.

- Matrix integrity

The swollen mass of the tablets remained intact or not was checked. Matrix integrity was observed throughout in vitro dissolution studies.

- Swelling index (14)

\section{Weight Gain and Water Uptake}

The swelling behavior of dosage units can be measured either by studying its dimensional changes, weight gain, or water uptake. The study is done by immersing the tablets in $0.1 \mathrm{~N} \mathrm{HCl}$ at $37^{\circ} \mathrm{C}$ and determining these factors at regular interval.

Water uptake (WU) is measured in terms of percent weight gain as given by equation below,

$$
W U=\left(W_{t}-W_{0}\right) \times 100 / W_{0}
$$

where, $W_{t}=$ final weight of the tablet at time $t$ and $W_{0}=$ initial weight of the tablet.

Tablets were removed at intervals of $2,4,6$, and $8 \mathrm{~h}$, excess water was blotted, and tablets were weighed. Water uptake is measured in terms of percent weight gain. This data is provided in Table II.

(b) In vitro drug release for all test formulations $(6,10,15,16)$

The in vitro drug release was studied by conducting dissolution test for tablets. Dissolution was carried out using USP XIII dissolution apparatus type II (paddle type). Nine hundred milliliters of $0.1 \mathrm{~N} \mathrm{HCl}$, which was maintained at $37^{\circ} \mathrm{C}$, was used as dissolution medium. The speed of paddle was maintained at $100 \mathrm{rpm}$. Five milliliters samples were withdrawn at the time intervals of $0.5,1,2,3,4,5,6,7$, and 8 and up to $18 \mathrm{~h}$ and replaced with equal volume of fresh dissolution medium maintained at same temperature. The samples were filtered and suitably diluted. Absorbances of these solutions were recorded at wavelength $290 \mathrm{~nm}$ using UV spectrophotometer. All the studies were carried out in triplicate.

\section{(c) Kinetic modeling of drug release}

The dissolution of all the batches of floating tablets of propranolol hydrochloride was carried out. The dissolution profile of all the batches was fitted to zero-order, first-order, Hixson-Crowell, Korsmeyer-Peppas, and Matrix models to ascertain the kinetic modeling of drug release. The reading was then processed for dissolution data using PCP Disso v3 software. Lag time was considered and all the data have been processed for fitting of the models.

(d) In vivo evaluation of gastrointestinal residence time of propranolol floating tablets

To confirm the spatial and temporary placement of floating drug delivery system, a variety of techniques have been used like string technique, endoscopy, gamma scintigraphy $(1,2,17-19)$. Of these techniques, X-ray technique was used to determine the gastric residence time of the tablets.

Floating tablets of the formulation $\mathrm{F}-\mathrm{V}$ were selected for in vivo gastrointestinal residence time studies.

For in vivo testing, healthy volunteers were selected. Volunteer was asked to swallow the tablet with sufficient water after meal in the afternoon under the supervision of registered doctor. This was noted as zero time reading. The successive images were then recorded at regular intervals over a period of 4-5 h. The X-ray of the tablet in the volunteers was recorded at intervals of $0.5,1$, and $4 \mathrm{~h}$.

\section{Tablet Preparation for In Vivo Studies (19)}

Tablets with diameter $11.5 \mathrm{~mm}$ and $336 \mathrm{mg}$ in weight were prepared. All the ingredients used in this study are transparent to X-ray, and therefore, to make the tablets X-ray opaque, the 
Table II. Swelling Study

\begin{tabular}{|c|c|c|c|c|}
\hline Formulation & Time (h) & $\begin{array}{l}\text { Initial } W_{t} \\
\left(W_{0}\right)(\mathrm{mg})\end{array}$ & $\begin{array}{l}\text { Final } W_{t} \\
\left(W_{t}\right)(\mathrm{mg})\end{array}$ & $\begin{array}{l}\text { Water } \\
\text { uptake }\end{array}$ \\
\hline \multicolumn{5}{|l|}{ Preliminary formulations } \\
\hline \multirow[t]{4}{*}{ II (HPMC K4 M 30\%) } & 2 & 204 & 403 & 97.54 \\
\hline & 4 & 201 & 561 & 178.910 \\
\hline & 6 & 196 & 689 & 251.53 \\
\hline & 8 & 298 & 791 & 299.49 \\
\hline \multirow[t]{4}{*}{ III (HPMC K4 M 40\%) } & 2 & 201 & 536 & 166.66 \\
\hline & 4 & 193 & 666 & 245.07 \\
\hline & 6 & 198 & 805 & 306.56 \\
\hline & 8 & 196 & 912 & 365.30 \\
\hline \multirow[t]{4}{*}{$X(X G 30 \%)$} & 2 & 205 & 519 & 188.29 \\
\hline & 4 & 193 & 678 & 251.29 \\
\hline & 6 & 195 & 787 & 303.54 \\
\hline & 8 & 199 & 865 & 334.67 \\
\hline \multirow[t]{4}{*}{ XI (XG 40\%) } & 2 & 196 & 598 & 205.10 \\
\hline & 4 & 198 & 752 & 279.79 \\
\hline & 6 & 205 & 834 & 306.82 \\
\hline & 8 & 201 & 901 & 348.25 \\
\hline \multirow[t]{4}{*}{ XII (XG 50\%) } & 2 & 201 & 659 & 227.86 \\
\hline & 4 & 206 & 881 & 327.66 \\
\hline & 6 & 199 & 1,051 & 428.14 \\
\hline & 8 & 201 & 1,189 & 491.54 \\
\hline \multicolumn{5}{|c|}{ Formulations of floating tablets } \\
\hline \multirow[t]{4}{*}{ F I } & 2 & 305 & 819 & 168.52 \\
\hline & 4 & 291 & 752 & 293.12 \\
\hline & 6 & 293 & 823 & 348.80 \\
\hline & 8 & 294 & 901 & 413.60 \\
\hline \multirow[t]{4}{*}{ F II } & 2 & 295 & 838 & 184.06 \\
\hline & 4 & 291 & 1,126 & 286.94 \\
\hline & 6 & 299 & 1,288 & 330.76 \\
\hline & 8 & 295 & 1,478 & 401.00 \\
\hline \multirow[t]{4}{*}{ F III } & 2 & 289 & 811 & 180.62 \\
\hline & 4 & 299 & 1,094 & 265.88 \\
\hline & 6 & 304 & 1,259 & 314.14 \\
\hline & 8 & 297 & 1,426 & 380.13 \\
\hline \multirow[t]{4}{*}{ F IV } & 2 & 294 & 804 & 173.46 \\
\hline & 4 & 293 & 1,096 & 274.06 \\
\hline & 6 & 299 & 1,303 & 357.78 \\
\hline & 8 & 302 & 1,491 & 393.70 \\
\hline \multirow[t]{4}{*}{ F V } & 2 & 299 & 817 & 173.24 \\
\hline & 4 & 295 & 1,119 & 270.32 \\
\hline & 6 & 295 & 1,305 & 343.37 \\
\hline & 8 & 298 & 1,489 & 399.66 \\
\hline
\end{tabular}

$n=3$

HPMC hydroxypropyl methyl cellulose, $F$ formulation

incorporation of $\mathrm{BaSO}_{4}$ was necessary. Barium sulfate has a high relative density $\left(4.4777 \mathrm{~g} / \mathrm{cm}^{2}\right)$ and poor floating properties. For in vivo tests, tablets with the following composition was compressed: $12 \%$ drug, $12 \%$ barium sulfate, HPMC K4 M 55.05\%, HPC 1.48\%, $\mathrm{NaHCO}_{3} 8.92 \%$, mannitol $3.57 \%$, microcrystalline cellulose $7.44 \%$, and magnesium stearate (1\%). Hardness was adjusted to $4.2 \mathrm{~kg} / \mathrm{cm}^{2}$.

\section{Formulation of Floating Tablets of Propranolol Hydrochloride}

Dissolution of all the formulations in Table I (preliminary formulations) was carried out. It was observed that drug release is controlled by the polymer type and its concentration. Many of the polymers used were found to be unsuitable for formulating floating tablets because of their lack of abilities to form matrix and control the release of drug or poor buoyancy shown by the formulations containing those particular polymers (Table III).

So, it was decided to use HPMC K4 M and HPC to formulate floating drug delivery system of propranolol hydrochloride (Table IV). Tablets were directly compressed with oval flat faced die punches of $8.5 \mathrm{~mm}$ diameter.

All the ingredients used in preliminary trials (i.e., sodium bicarbonate and magnesium stearate $(1 \%)$ ) were kept constant only except Avicel (microcrystalline cellulose) which was used in formulation of floating tablets of propranolol hydrochloride because sometimes release from matrix made up of high concentration of HPMC is incomplete and Avicel addition could increase the release rate at later stage (12).

\section{(e) Similarity factor}

In vitro release profile of the marketed Ciplar LA tablets was performed under similar conditions as used for in vitro release testing of the test product The similarity factor between the two formulations (Ciplar LA and formulation V) was determined using the data obtained from the drug release studies. The data were analyzed by the following formula.

$$
\left.f_{2}=50 \log \left\{(1+1 / N) \sum\left(R_{i}-T_{i}\right)^{2}\right)^{-0.5}\right\} \times 100
$$

where $N=$ number of time points, $R_{i}$ and $T_{i}=$ dissolution of reference and test products at time $i$. If $f_{2}$ is greater than 50 , it is considered that two products share similar drug release behaviors.

\section{RESULTS}

\section{Evaluation of powder blend}

Values of angle of repose were found to be between $28.00^{\circ}$ and $31.37^{\circ}$. Hausner ratio for all preliminary formulations was between 1.17 and 1.32 .

$$
\text { Housner ratio }=T B D / L D D
$$

The powder blend with Hausner ratio of 1.25 has good flow properties so these values showed that the powder blend had acceptable flow properties.

Percent compressibility was in the range of 13 to 21 .The value between 12 to 20 has good compressibility which indicate that powder blend is an acceptable range (20).

\section{Evaluation of matrix tablets}

Results for hardness, friability, and content uniformity are indicated in Table $\mathrm{V}$ and were found to be well within the limits (USP).

Matrix Integrity. The tablet matrices for the formulations with HPMC K4 M 40\% and 50\% (II, III), xanthan gum (VII, VIII, IX), and propranolol hydrochloride floating formulations from (FI, FII, FIII, FIV, FV) were seen to be intact throughout the dissolution studies. Tablets containing HPC and HPMC E $15 \mathrm{LV}$ and sodium alginate did not pass this test. 
Table III. In Vitro Dissolution Data of Tablet Formulations for Preliminary Trials

\begin{tabular}{|c|c|c|c|c|c|}
\hline & Floating lag time (min) & Floating time (h) & Matrix integrity & $T_{50} \pm \mathrm{SD}(\mathrm{h})$ & $T_{85} \pm \mathrm{SD}(\mathrm{h})$ \\
\hline I & - & - & - & $0.38 \pm 0.01$ & $0.82 \pm 0.01$ \\
\hline II & $<1$ & 24 & + & $2.8 \pm 0.28$ & $6.2 \pm 0.1$ \\
\hline III & $<1$ & 24 & + & $4.4 \pm 0.15$ & $8.2 \pm 0.05$ \\
\hline IV & - & - & - & $0.2 \pm 0.005$ & $0.4 \pm 0.02$ \\
\hline $\mathrm{V}$ & - & - & - & $0.30 \pm 0.02$ & $1.1 \pm 0.12$ \\
\hline VI & - & - & - & $0.29 \pm 0.01$ & $1.03 \pm 0.06$ \\
\hline VII & - & - & - & $0.38 \pm 0.01$ & $0.38 \pm 0.02$ \\
\hline VIII & - & - & - & $0.39 \pm 0.01$ & $0.38 \pm 0.02$ \\
\hline IX & - & - & - & $0.43 \pm 0.02$ & $1.1 \pm 0.1$ \\
\hline $\mathrm{X}$ & - & - & + & $4.9 \pm 0.31$ & - \\
\hline XI & $>1$ & - & + & $8.2 \pm 0.26$ & - \\
\hline XII & $<1$ & - & + & $10.1 \pm 0.21$ & - \\
\hline XIII & $<1$ & - & - & $0.29 \pm 0.01$ & $0.91 \pm 0.01$ \\
\hline XIV & - & - & - & $0.31 \pm 0.01$ & $0.88 \pm 0.03$ \\
\hline$X V$ & - & - & - & $0.31 \pm 0.02$ & $0.88 \pm 0.02$ \\
\hline
\end{tabular}

$S D$ standard deviation

Water uptake was calculated for formulations which passed matrix integrity test. Results are shown in Table II.

Release profile of different formulations of floating tablets of propranolol hydrochloride was determined by in vitro dissolution (Fig. 1).

On comparing the release of formulations F I, II, III, IV, and $\mathrm{V}$, it was seen that release of formulation $\mathrm{F} \mathrm{V}$ is nearly same as that of marketed formulation (Fig. 2).

\section{Release Kinetics for Formulations of Floating Tablets}

To know mechanism of drug release from these formulations, the data were treated with various models such as zero-order, first-order, matrix (Higuchi), Hixson-Crowell, and Korsmeyer-Peppas. Different results that were obtained and the model which best fits the drug release from different formulations are shown in Table VI.

The limits for release of propranolol from extended release propranolol hydrochloride capsule (21) are stated in Table VII. So formulation F V was considered to be as the final optimized formulation. Similarity factor for the Ciplar LA and formulation $\mathrm{V}$ has been given in Table VIII.

\section{In Vivo Evaluation}

In vivo evaluation was carried out in fed state. The behavior of tablet was studied in three volunteers in real time using radiographic imaging technique.
Figure 3a shows X-ray taken $0.5 \mathrm{~h}$ after administration of tablet. Tablet can be seen in the stomach. Next image, Fig. 3b, taken at $1 \mathrm{~h}$ shows change in position of tablet; this shows that tablet did not adhere to gastric mucous. Also, swelling of the tablet can be visualized.

Next image, Fig. 3c, taken at $4 \mathrm{~h}$ after administration of tablet shows tablet traveled further down the stomach.

The amount of barium sulfate was sufficient to ensure visibility by $\mathrm{X}$-ray and at the same time was low enough to enable tablets to float. It can be seen that these tablets had density greater than tablets from formulation $\mathrm{F} \mathrm{V}$ and they had floating lag time of 5 to $9 \mathrm{~min}$. But the tablets containing $\mathrm{BaSO}_{4}$ were identical with tablet formulation $\mathrm{F} \mathrm{V}$ in regards of other ingredients, their quantities, and hardness. In same pattern, it is seen in the in vivo study that tablet remained in GIT for $4 \mathrm{~h}$ in all the volunteers.

\section{DISCUSSION}

It was concluded from the results of powder blend that it has good flow properties. Also, the results for hardness, friability, uniformity of content, and uniformity of mass were well within the limit.

\section{In Vitro Buoyancy Studies}

Buoyancy lag time was less than 1 min only for formulations containing $40 \%$ and 50\% HPMC K4 M. Rest of the formulations failed to float. Tablets formulated with

Table IV. Formulations of Floating Tablets of Propranolol Hydrochloride

\begin{tabular}{|c|c|c|c|c|c|}
\hline Ingredients & F I & F II & F III & F IV & F V \\
\hline 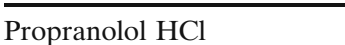 & 40 & 40 & 40 & 40 & $\overline{40}$ \\
\hline HPMC K4 M & 85 & 110 & 135 & 160 & 185 \\
\hline HPC & 105 & 80 & 55 & 30 & 5 \\
\hline Sodium bicarbonate $(10 \%)$ & 30 & 30 & 30 & 30 & 30 \\
\hline Microcrystalline cellulose & 37 & 37 & 37 & 37 & 37 \\
\hline Magnesium stearate $(1 \%)$ & 3 & 3 & 3 & 3 & 3 \\
\hline
\end{tabular}

Total weight of tablet $300 \mathrm{mg}$. All weights in milligrams

$F$ formulation, HPMC hydroxypropyl methyl cellulose, HPC hydroxypropyl cellulose 
Table V. Results for Evaluation of Tablet

\begin{tabular}{lccc}
\hline Formulations & $\begin{array}{l}\text { Hardness }^{\mathrm{a}} \\
\left(\mathrm{kg} / \mathrm{cm}^{2}\right)\end{array}$ & $\begin{array}{l}\text { Friability } \\
(\%)\end{array}$ & $\begin{array}{l}\text { Content uniformity } \\
(\%)\end{array}$ \\
\hline I & $3.76 \pm 0.15$ & 0.53 & $97.60 \pm 1.65$ \\
II & $3.93 \pm 0.15$ & 0.52 & $99.01 \pm 1.51$ \\
III & $4.13 \pm 0.11$ & 0.24 & $97.77 \pm 0.43$ \\
IV & $4.06 \pm 0.25$ & 0.27 & $96.70 \pm 0.80$ \\
V & $4.06 \pm 0.25$ & 0.80 & $99.25 \pm 0.65$ \\
VI & $4.03 \pm 0.057$ & 0.37 & $97.85 \pm 2.58$ \\
VII & $3.9 \pm 0.2$ & 0.57 & $98.84 \pm 1.17$ \\
VIII & $4.03 \pm 0.2$ & 0.27 & $98.02 \pm 0.74$ \\
IX & $4.06 \pm 0.25$ & 0.76 & $97.19 \pm 0.76$ \\
X & $3.73 \pm 0.11$ & 0.59 & $96.12 \pm 0.20$ \\
XI & $3.66 \pm 0.057$ & 0.53 & $98.51 \pm 0.43$ \\
XII & $3.83 \pm 0.057$ & 0.46 & $98.20 \pm 0.99$ \\
XIII & $4.06 \pm 0.25$ & 0.56 & $97.44 \pm 0.52$ \\
XIV & $3.66 \pm 0.11$ & 0.25 & $97.11 \pm 1.17$ \\
XV & $3.9 \pm 0.26$ & 0.22 & $99.17 \pm 0.87$ \\
F I & $4.03 \pm 0.11$ & 0.31 & $98.35 \pm 0.57$ \\
F II & $4.16 \pm 0.11$ & 0.14 & $96.28 \pm 0.86$ \\
F III & $3.96 \pm 0.15$ & 0.48 & $97.36 \pm 0.14$ \\
F IV & $3.9 \pm 0.26$ & 0.34 & $98.84 \pm 0.14$ \\
F V & $3.93 \pm 0.15$ & 0.23 & $96.61 \pm 1.14$ \\
III & 3.93 & \\
\hline
\end{tabular}

${ }^{a}$ All values are expressed as mean $\pm \mathrm{SD}, n=3$

$F$ formulation

HPMC E 15 LV, HPC, and sodium alginate failed matrix integrity test as tablets disintegrated within 2-3 h.

Results of percent water uptake show that as the polymer concentration increases, the water uptake also increases.

All tablets formulated with HPMC K4 M and xanthan gum showed good swelling radially as well as axially.

\section{Floating Behavior of Tablets}

Formulations containing HPMC K4 M (formulations II and III from preliminary trials) showed the best buoyancy among all the formulations. The formulations (i.e., FI, FII, FIII, FIV, FV) showed good floating properties and remained buoyant for more than $24 \mathrm{~h}$. Floating lag time for these tablets was less than $1 \mathrm{~min}$. Formulation I (containing 30\% HPMC $\mathrm{K} 4 \mathrm{M}$ ) disintegrated and released the drug completely in $1 \mathrm{~h}$ so did not show any floating.

Release Profile of Formulations FI, FII, FIII, FIV, FV.

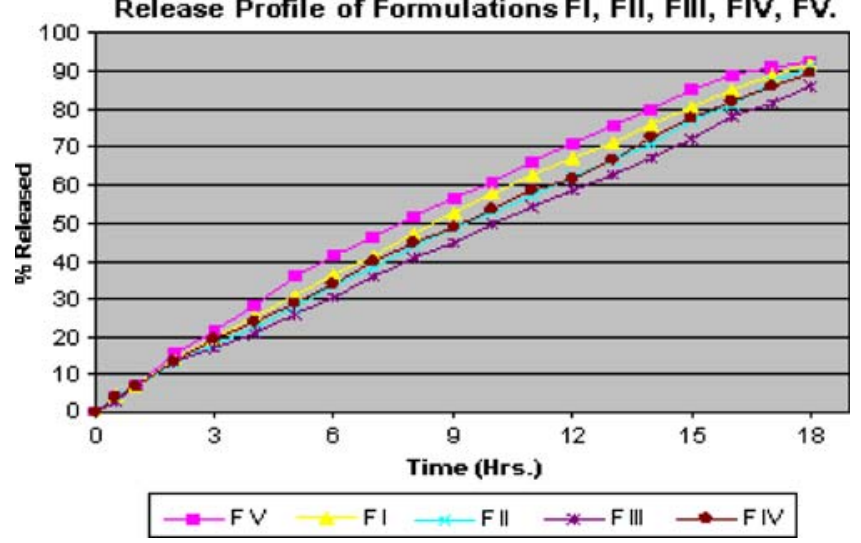

Fig. 1. Release profile for formulations of floating tablets

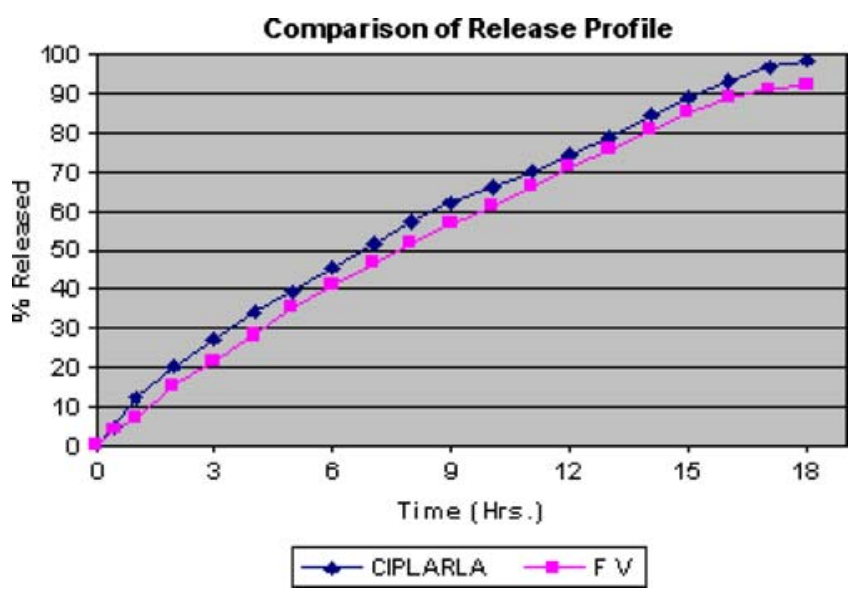

Fig. 2. Comparison of release of profile of marketed formulation (CIPLAR LA $40 \mathrm{mg}$ ) and formulation FV

Sodium bicarbonate induced $\mathrm{CO}_{2}$ generation in the presence of dissolution medium $(0.1 \mathrm{~N} \mathrm{HCl})$. The gas generated is trapped and protected within the gel, formed by hydration of polymer, thus decreasing the density of the tablet. As the density of the tablet falls below 1, the tablet becomes buoyant.

All three formulations containing HPMC E $15 \mathrm{LV}$ (formulations IV, V, VI), HPC (formulations VII, VIII, IX), and sodium alginate (formulations XIII, XIV, XV) disintegrated immediately so did not show any floating. These formulations failed in matrix integrity test as these formulations disintegrated within 1 to $2 \mathrm{~h}$ and released the drug. Therefore, these polymers were not considered as candidates for formulating floating tablets of propranolol hydrochloride.

Tablets containing xanthan gum showed poor floating characteristics. The matrix formed was not good enough to hold the bubbles and float. It was found that tablets containing higher proportions of xanthan gum showed better floating properties than one with lower polymer concentration. But the tablets containing $30 \%$ and $40 \%$ polymer showed indifferent floating as they were sometimes floating in the middle of dissolution flask and not at the upper surface of the dissolution medium.

Thus, xanthan gum failed to form a matrix of sufficient strength; therefore, xanthan gum was not considered while formulating floating tablets.

\section{Effect of Various Polymers on Drug Release (Matrix Integrity)}

From release profile data of preliminary studies, it can be concluded that tablets with $30 \%$ HPMC K4 M disintegrated and completely released drug in $1 \mathrm{~h}$. As the concentration of HPMC K4 M was increased, it showed good control in drug release as well as the floating properties also improved.

HPMC forms a hydrogel in contact with acidic fluid. Thus, it helps tablet to swell and float. HPMC grade K4 M is high viscosity grade of hydroxypropyl methylcellulose and forms a better matrix, in which $\mathrm{CO}_{2}$ released from gas generating agent, than many of the other polymers.

Therefore, HPMC K4 M at high concentration was considered to be ideal polymer for formulating floating tablets of propranolol hydrochloride. 
Table VI. Kinetic Treatment of Floating Matrix Tablet

\begin{tabular}{lccccc}
\hline & Zero-order plot & First-order plot & Korsmeyer-Peppas plot & Matrix (Higuchi) plot & Hixson-Crowell plot \\
\cline { 2 - 6 } Formulation & $R^{2}$ & $R^{2}$ & $R^{2}$ & $R^{2}$ & $R^{2}$ \\
\hline Ciplar LA & 0.9531 & 0.9870 & 0.9964 & 0.9 & 0.9971 \\
F I & 0.9687 & 0.9866 & 0.9 & 0.9 & 0.9973 \\
F II & 0.9718 & 0.9820 & 0.9 & 0.9724 & 0.9950 \\
F III & 0.9723 & 0.9820 & 0.9970 & 0.9758 & 0.9958 \\
F IV & 0.9703 & 0.9856 & 0.9976 & 0.9914 & 0.9966 \\
F V & 0.9627 & 0.9895 & 0.9870 & & 0.9978 \\
\hline
\end{tabular}

$F$ formulation

Tablets formulated with HPMC E $15 \mathrm{LV}$ could not retain the drug. The viscosity of $2 \% w / v$ solution of HPMC E $15 \mathrm{LV}$ is about $12-18 \mathrm{mPa}$. It is very less as compared to HPMC K4 $\mathrm{M}(4,000 \mathrm{mPa})$. So, it did not retain any drug as matrix of required strength to trap the bubbles of $\mathrm{CO}_{2}$ was not formed. No matrix was formed in the formulations formulated with this polymer and the tablets disintegrated releasing the drug in $1 \mathrm{~h}$. Therefore, HPMC E $15 \mathrm{LV}$ was not considered for formulating floating tablets.

Tablets formulated with this HPC HF could not retain the drug. All tablets released the drug completely in about $2 \mathrm{~h}$. Matrix was not formed with HPC (Klucel HF) when it was formulated as tablets by direct compression technique. HPC is freely soluble in water below $38^{\circ} \mathrm{C}$ (solubility one in two parts); in hot water, it is insoluble and is precipitated as a highly swollen floc at a temperature between $40^{\circ} \mathrm{C}$ to $45^{\circ} \mathrm{C}$ (15). So, maybe it could not retain the drug in the dissolution conditions used. Though HPC when used alone failed to retain the drug release, it was still used to formulate long acting floating tablet of propranolol hydrochloride.

Tablets formulated with xanthan gum showed good control in drug release. Xanthan gum is natural polysaccharide which swells and controls the drug release. But tablets with polymer concentration of $30 \%$ and $40 \%$ showed poor floating properties.

Also, as the concentration of polymer was increased, it retained the drug for longer time.

Tablets with $50 \%$ polymer retained the drug for more time as compared with same concentration of HPMC K4 M.

But due to poor floating properties, they were not considered for formulating floating tablets of propranolol hydrochloride.

Tablets with sodium alginate completely released the drug in $1 \mathrm{~h}$. Independent of polymer concentration, all the tablets disintegrated immediately without showing any drug

Table VII. Limits for Percent Drug Released from Extended Release Propranolol Hydrochloride Capsules

\begin{tabular}{clc}
\hline Time $(\mathrm{h})$ & $\begin{array}{l}\text { \% Release } \\
\text { (USP standard) }\end{array}$ & $\begin{array}{l}\text { Observed release } \\
\text { for F V (\%) }\end{array}$ \\
\hline 0.5 & NMT 30 & 12 \\
4 & $35-60$ & 28.16 \\
8 & $55-80$ & 51.88 \\
14 & $70-95$ & 80.32 \\
24 & $81-110$ & $>92$ \\
\hline
\end{tabular}

USP US Pharmacopeia, NMT not more than, $F$ formulation retention. This might have occurred as the grade of sodium alginate used was Keltose which has low swelling and high erosion rate properties (14).

\section{Kinetic Modeling}

Whenever a new solid dosage form is developed or produced, it is necessary to ensure that drug dissolution occurs in an appropriate manner. The quantitative analysis of the values obtained in dissolution/release tests is easier when mathematical formulas that express the dissolution results as a function of some of the dosage forms characteristics are used. In some cases, these mathematic models are derived from the theoretical analysis of the occurring process. In most of the cases, the theoretical concept does not exist and some empirical equations have proved to be more appropriate. Drug dissolution from solid dosage forms has been described by kinetic models in which the dissolved amount of $\operatorname{drug}(Q)$ is a function of the test time, $t$. Some analytical definitions of the $Q(t)$ function are commonly used, such as zero-order, first-order, Hixson-Cro-

Table VIII. Similarity factor $\left(f_{2}\right)$

\begin{tabular}{lccc}
\hline & \multicolumn{2}{c}{ Average \% release } & \\
\cline { 2 - 3 } Time (h) & Ciplar LA (reference) & Formulation V (test) & $f_{2}{ }^{\text {a }}$ \\
\hline 0 & 0 & 0 & 0 \\
0.5 & 5.09 & 4.33 & 97.25 \\
1 & 12.48 & 7.18 & 74.50 \\
2 & 20.32 & 15.56 & 71.47 \\
3 & 27.29 & 21.61 & 68.78 \\
4 & 34.18 & 28.16 & 65.02 \\
5 & 39.58 & 35.66 & 65.40 \\
6 & 45.67 & 41.33 & 65.89 \\
7 & 51.88 & 46.47 & 65.26 \\
8 & 57.29 & 51.88 & 64.92 \\
9 & 62.35 & 56.52 & 64.65 \\
10 & 66.04 & 60.9 & 64.54 \\
11 & 70.23 & 66.04 & 64.87 \\
12 & 74.61 & 71.14 & 65.20 \\
13 & 78.99 & 75.83 & 65.66 \\
14 & 84.24 & 80.32 & 65.85 \\
15 & 88.77 & 84.89 & 66.12 \\
16 & 93.11 & 89.07 & 66.22 \\
17 & 96.73 & 90.94 & 65.95 \\
18 & 98.1 & 92.35 & 65.57 \\
\hline
\end{tabular}

${ }^{a}$ Average value of $f_{2}=64.25$ 

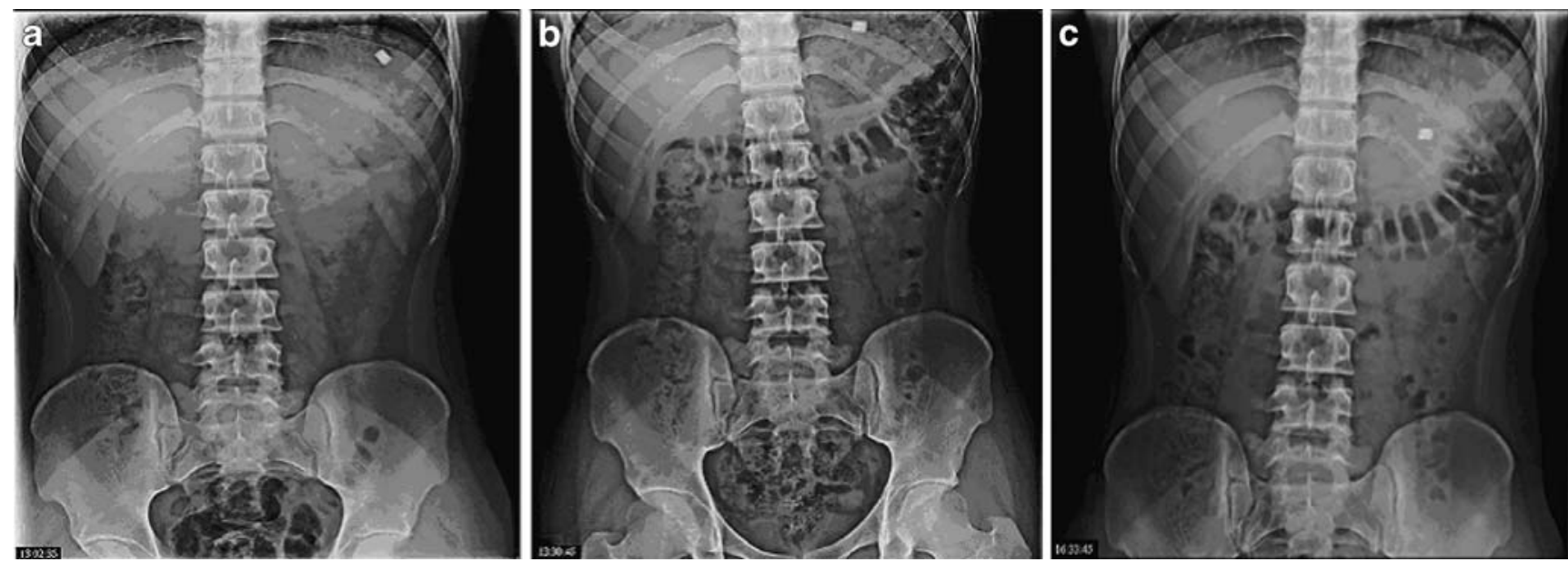

Fig. 3. a-c X-rays indicating position of floating tablet in gastrointestinal tract of volunteer. a X-ray taken at $0.5 \mathrm{~h}$. b X-ray taken at $1 \mathrm{~h}$. $\mathbf{c} \mathrm{X}$-ray taken at $4 \mathrm{~h}$

well, Weibull, Higuchi, Baker-Lonsdale, Korsmeyer-Peppas, and Hopfenberg models (22).

For formulation V and Ciplar LA, $R^{2}$ values for HixsonCrowell model were slightly higher than the other models, showing a better conformance to this model (Table VI), following the equation

$$
(\% \text { unreleased })^{1 / 3}=k t
$$

where $t$ is time and $k$ is the rate constants.

Applicability of the release curves to Hixson-Crowell model indicated that the dissolution occurs in the planes that are parallel to drug surface and the tablet dimensions diminish proportionally to keep geometric forms constant all the time. For both the formulations $\mathrm{V}$ and Ciplar LA, the release rate is limited by the drug particles dissolution rate and not by the diffusion that might occur through the polymer matrix. Thus, formulation $\mathrm{V}$ and Ciplar LA indicated a change in surface area and diameter of the tablets, with a progressive dissolution of the matrix as a function of time. This result was similar to that obtained elsewhere for the release of diltiazem $\mathrm{HCl}$ from matrix tablets (23).

For formulations I, II, III and IV followed KorsmeyerPeppas model (Table VI) and the release is given by the following equation

$$
\begin{aligned}
\% \text { Released } & =k(\text { Time })^{n} \text { OR } \log (\% \text { Released }) \\
& =\log (k)+n \cdot \log (\text { Time })
\end{aligned}
$$

where $t$ is time and $k$ is the rate constants.

For formulations I, II, III, and IV, the release mechanism is not well known, or more than one type of release phenomena is involved as Fickian diffusion (Higuchi matrix), anomalous transport, and zero-order release. This result was similar to that obtained oral floating matrix tablet formulation of diltiazem hydrochloride (24).

\section{Similarity Factor}

Dissolution testing is carried out to check quality control, uniformity from batch to batch. It gives idea to predict bioavailability for prepared formulation with the existing one.
The so called $f_{2}$ method can be used to compare two dissolution profiles. Similarity factor analysis between the formulation V and Ciplar LA showed an $f_{2}$ factor $\left(f_{2}=64.65\right)$ greater than 50 , as shown in Table VIII, which confirm the similarity in release of both the test and marketed.

\section{CONCLUSION}

Propranolol hydrochloride floating tablets were prepared by blending drug, HPMC, HPC, gas generating agent, and diluents followed by direct compression. The matrix tablets swelled while in contact with the aqueous medium. Tablets formulated with HPC, sodium alginate, and HPMC E $15 \mathrm{LV}$ failed to produce matrix of required strength. The formulations containing xanthan gum showed good drug retaining abilities but floating abilities were found to be poor. It was concluded formulation V containing HPMC K4 M gave the best in vitro release of $92 \%$ in $18 \mathrm{~h}$. In vivo evaluation by X-ray technique showed that tablet was retained in the stomach for $4 \mathrm{~h}$.

\section{REFERENCES}

1. Singh BN, Kim KH. Floating drug delivery systems: an approach to oral controlled drug delivery via gastric retention. J Control Release. 2000;63:235-59. Review.

2. Chawla G, Gupta P, Bansal AK. In: Jain NK, editor. Progress in controlled and novel drug delivery. 1st ed. New Delhi: CBS; 2001. p. 76-97.

3. Tripathi KD. Antihypertensive drugs, essentials of medical pharmacology. 5th ed. New Delhi: Jaypee Brothers; 2003. p. 235-6.

4. Woodlinger AM. Cardiovascular drugs. In: Troy DB, editor. Remington the science and practice of pharmacy, Indian edition. 21st ed. Philadelphia: Lippincott Williams and Wilkins; 2005. p. 1350.

5. Williams DA, Temke TL. Foyes principles of medicinal chemistry, International student edition. Philadelphia: Lippincott Williams and Wilkins; 2002. p. 489-93.

6. Indian Pharmacopoeia. Government of India, Ministry of Health and Family Welfare, vol. II. Delhi: The Controller of Publication; 1996. p. 634.

7. Davis SS. Formulation strategies for absorption windows. Drug Discov Today. 2005;10(4):250.

8. Singh BN, Kim KH. Encyclopedia of pharmaceutical technology, drug delivery: oral route. New York: Marcel Dekker; 2001. p. 1253. 
9. Khattar D, Ahuja A, Khar RK. Hydrodynamically balanced systems as sustained release dosage forms for propranolol hydrochloride. Pharmazie. 1990;45(5):356-8.

10. Bodea A, Leucuta SE. Optimization of propranolol hydrochloride sustained release pellets using factorial a design. Int J Pharm. 1997;154:49-54.

11. Narendra C, Srinath MS, Babu G. Optimization of bilayer floating tablet containing metoprolol tartarate as a model drug for gastric retention. AAPS Pharm Sci Tech. 2006;7(2):Article 34.

12. Ali J, Ahuja A, Khar RK, Baboota S. Formulation and development of hydrodynamically balanced system for metformin. Eur J Pharm Biopharm. 2007;67:196-201.

13. Basak SC, Rao KN, Manavalan R, Rao PR. Development and in vitro evaluation of floating matrix tablet of ciprofloxacin. Indian $\mathrm{J}$ Pharm Sci. 2004;66(3):313-6.

14. Sriamornsak P, Thirawong N, Korkard K. Swelling, erosion and release behavior of alginate-based matrix tablets. Eur. J. Pharm. Biopharm. 2007;66:435-50.

15. Huang YB, Tsai YH, Yang WC, Wu PC, Chang JS. Influence of formulation variables and manufacturing process on propranolol extended release profile from HPMC matrices tablets. J Appl Polymer Sci. 2004;93(4):1886-90.

16. Huang YB, Tsai YH, Yang WC, Wu PC, Chang JS. Optimization of sustained release propranolol dosage form using factorial design and response surface methodology. Biol Pharm Bull. 2004;27(10):1626-9.

17. Garg S, Sharma S. Gastroretentive drug delivery systems. Business briefings. Pharmatech. 2003;162.

18. Arora S, Ali J, Ahuja A, Khar RK, Baboota S. Floating drug delivery systems: a review. AAPS PharmSciTech. 2005;6(3):Article 47.

19. Baumgartner S. Optimisation of floating matrix tablets and evaluation of their gastric residence time. Int. J. Pharm. 2000;195:125-35.

20. Staniforth J. In: Aulton ME, editor. Pharmaceutics: the science of dosage form design. 2nd ed. London: Churchill Livingstone; 2002. p. 207-8.

21. USP NF. The official compendia of standards. The United States Pharmacopoeial Convention. Asian edition. Propranolol extended release capsules. 2006;3115.

22. Costa P, Sousa Lobo JM. Review: modeling and comparison of dissolution profiles. Eur J Pharm Sci. 2001;13:123-33.

23. Gohel MC, Amin AF, Patel KV, Panchal MK. Studies in release behavior of diltiazem $\mathrm{HCl}$ from matrix tablets containing (hydroxypropyl) methyl cellulose and xanthan gum. Boll. Chim. Farm. 2002;141:21-8.

24. Gambhire MN, Ambade KW, Kurmi SD, Kadam VJ, Jadhav KR Development and in vitro evaluation of an oral floating matrix tablet formulation of diltiazem hydrochloride. AAPS PharmSciTech. 2007;8(3):Article 73. 